\title{
Did the Financial Crisis affect the Market Valuation of Large
}

\section{Systemic U.S. Banks?}

\author{
Georgios Bertsatos ${ }^{1}$, Plutarchos Sakellaris ${ }^{2}$, Mike G. Tsionas ${ }^{3, *}$
}

September 2017

\begin{abstract}
We examine the impact of the financial crisis on the stock market valuation of large and systemic U.S. bank holding companies (BHCs). Using the Bertsatos and Sakellaris (2016) model of fundamental valuation of bank equity, we provide evidence that the financial crisis has not altered investors' attitudes towards bank characteristics. In particular, before, during, and after the crisis, investors in large and systemic U.S. BHCs seemed to penalize leverage, albeit temporarily. Both before and after the crisis, they reward size in the short run. This pattern is appearing only briefly during the crisis. We also show that bank opacity plays no role in market valuation either in the short run or in the long run. Last but not least, we find evidence that stress testing has been informative to the market and that those BHCs that failed at the post-crisis stress tests were not subsequently valued differently by the market.
\end{abstract}

JEL classification: G01; G10; G21; G28

Keywords: Valuation; Systemic U.S. BHCs; Financial Crisis; Stress testing; Co-integration

1 Ph.D. Candidate at Athens University of Economics and Business, Department of Economics, Patission 76, Athens, 104 34, Greece. E-mail address: bertsatosg@aueb.gr

2 Professor at Athens University of Economics and Business, Department of Economics, Patission 76, Athens, 104 34, Greece. E-mail address: plutarch@aueb.gr

3 Professor, Lancaster University Management School, LA1 4YX, U.K., and Athens University of Economics and Business, Department of Economics, Patission 76, Athens, 104 34, Greece. E-mail address: m.tsionas@lancaster.ac.uk

* Corresponding author. 


\section{Introduction}

The valuation by market participants of U.S. bank holding companies' (BHCs) stock has fluctuated considerably over the decade of 2004 to 2014. As regards the price-to-book ratio of equity (PB), we have also observed large, secular declines during and after the financial crisis that erupted in 2007. Calomiris and Nissim (2014) document this secular decline for the universe of U.S. BHCs and explain it in terms of declines in the values of intangibles along with unrecognized contingent obligations. The declines in market valuation have been particularly sharp for the group of very large and systemic U.S. BHCs - a group that has received substantial scrutiny by the market. These are the BHCs that participated in a series of capital assessment exercises and stress tests conducted by U.S. federal regulators starting in 2009 and include eight Global Systemically Important Banks (GSIBs).

Given the unprecedented scrutiny that these BHCs have been subjected to, we ask whether this has altered the way in which investors value these BHCs and at the same time whether stress testing has been informative to the market. Previewing our results, the answer is: not significantly so. To be clear, we do not explore explanations of the secular decline in the PB ratios of bank equity, a matter that has been addressed convincingly by Calomiris and Nissim (2014). These changes in market PB ratios are best thought of as reflecting broadly corresponding changes in equilibrium valuations. Instead, we investigate to what extent short-run deviations between market PB ratios and their fundamental values have changed in nature after the financial crisis and the imposition of the new regulatory requirements. Instead of the cross-sectional variation of PB ratios, we focus on the time-series crosssectional variation of $\mathrm{PB}$ ratios with co-integrating techniques. Another feature that differentiates our work from Calomiris and Nissim (2014) is that we concentrate only on the 
group of the largest U.S. BHCs. ${ }^{4}$ We contrast market movements in BHCs' PB ratios to those derived from the Dynamic Dividend Discount Model (3DM), a model of fundamental valuation developed by Bertsatos and Sakellaris (2016), and analyze divergences between these two valuations. 3DM has attractive features: it establishes an equilibrium relationship among the PB ratio of equity and measures of fundamentals such as the cost of equity, the expected growth of net income (NI) and modified dividend payout ratio (DPR), and allows for temporary deviations from that relationship.

Our empirical work proceeds in two steps. First, we establish that for large and systemic U.S. BHCs there is an economically meaningful and stable long-run equilibrium relationship between the PB ratio of equity and the aforementioned fundamental variables. Second, we examine whether any short-run divergences of market valuation from this equilibrium relationship are related systematically to observable bank characteristics such as leverage, opacity and size. A striking result that we obtain is that, at any given point in time, there is a large heterogeneity in the degree to which PB ratios of these BHCs are temporarily above or below their long-run equilibrium valuation. Furthermore, these divergences are rather persistent over time. On average, less than three tenths of the gap closes each quarter. We show that divergences from fundamental valuation in PB ratios are created as the market, in general, under-reacts in the short run to changes in fundamentals. The degree of divergence depends on bank characteristics such as leverage and size but not on opacity. In the long run, we show that the estimates of fundamental PB ratios given by 3DM have properly priced risk, growth and cash flows, as proxied by cost of equity, expected growth of net income and modified dividend payout ratio, respectively, throughout the period examined.

\footnotetext{
4 The BHCs in our sample are substantially larger (minimum value of assets is 28.6 billion USD) than those classified as large BHCs in their sub-sample (minimum value is 2 billion USD).
} 
We find that short-run divergences between market and fundamental valuation are related systematically to observable bank characteristics such as leverage and size controlling for various macroeconomic variables. In particular, the market tended to temporarily undervalue BHCs with higher leverage, relative to their fundamental valuation, throughout the period we are analyzing. Size seems to have had a positive effect before and after the crisis. In other words, larger BHCs displayed higher overvaluation relative to fundamentals, albeit temporarily so. This effect temporarily disappeared during the crisis but returned after the crisis. We also examine the role of bank opacity and find that it does not affect market participants' valuations in the short run. ${ }^{5}$ On the whole, these results indicate that the recent financial crisis has not altered substantially the way that market participants value very large and systemic U.S. BHCs. Moreover, we find evidence that either the GSIB status or the failure at the post-crisis stress-testing exercises (Comprehensive Capital Analysis Review, CCARs) have not affected market valuation of their PB ratios. The only exception is the earlier stress test, i.e. the Supervisory Capital Assessment Program (SCAP), which seems to have had a negative effect on PB market valuation for the failed BHCs. Last but not least, we find evidence that stress testing was informative to the market participants.

In the next section, we present the model of fundamental share valuation, and in section three we discuss our empirical analysis and findings. Finally, in section four we offer some concluding remarks.

\footnotetext{
5 There may be other reasons that market valuation of banks could show (persistent) divergences from fundamental valuation. For example, emerging markets developments, exposure to certain commodities such as oil, fines and impending settlements, and most recently prospects of negative deposit interest rates. Incorporating these are out of the paper's scope. We thank an anonymous referee for this comment.
} 


\section{A Bank Valuation Model}

We compute the fundamental values of the BHCs in our sample applying the 3DM of Bertsatos and Sakellaris (2016). According to 3DM, there is an equilibrium relationship between the PB ratio and the cost of equity, expected growth of net income and modified dividend payout ratio.

$$
P B=f\left(\stackrel{-}{r}, g_{N I}^{+}, \stackrel{+}{D P R}\right)
$$

This equilibrium relationship holds the same for all BHCs in the panel, and is approximated in estimation by a second-order Taylor expansion of $f($.$) . 3DM then applies$ the Pooled Mean Group (PMG) method of Pesaran et al. (1999) that allows PB ratios to diverge from this equilibrium relationship temporarily. The degree of persistence in such divergence is heterogeneous to each BHC in the panel.

Using the estimates of the long-run relationship (1), we calculate the predicted PB ratios. These are the PB values that would prevail under the estimated model if bank values were at long-run equilibrium.

\section{Results and Discussion}

\subsection{Data Description}

The BHCs in our sample participated in the 2008 Trouble Asset Relief Program (TARP), 2009 Supervisory Capital Assessment Program (SCAP), 2011, 2012, 2013 and 2014 Comprehensive Capital Analysis Review (CCAR), and 2013 and 2014 Dodd-Frank Act Stress Tests (DFAST) exercises conducted by the Fed. Data used is quarterly, from 2003:Q4 to 2014:Q1, i.e. $T=42$, and refers to values at the end of each quarter. We collected data from Datastream mainly and secondarily from BHCs' SEC filings (10-K and 10-Q) when this was necessary. The aggregate number of BHCs that participated in the 2008 TARP, 2009 
SCAP and the consecutive CCARs is 31 . Since six of them are either unlisted or subsidiaries of international holding companies and for one of them we have small number of observations, our sample is reduced to 24 BHCs.

\section{Data Construction:}

We define PB ratio as the market value of equity over its book value at the end of each quarter. There are two issues with this definition that we must address. First, that valuation models reflect the price of a common share. Therefore, all non-common equity should be excluded and only common equity should be used. Second, that at each quarter's end, investors do not know the true value of $\mathrm{PB}$, because the quarter-end's book value of common equity (BVCE) gets published one or two months later. We assume that, in order to calculate $\mathrm{PB}$ at quarter-end, investors use in the denominator a forecast of this quarter-end BVCE.

The estimated PB ratio with the forecast of BVCE is constructed as follows: We make this forecast by multiplying the last quarter's (known) BVCE with $(1+g)$, where $g$ is the average of the last five BVCE growth rates, i.e.:

$$
g_{t}=\frac{\sum_{i=1}^{5}\left(\frac{B V(C E)_{t-i}-B V(C E)_{t-i-1}}{B V(C E)_{t-i-1}}\right)}{5}
$$

where, $B V(C E)_{t-i}$ is the BVCE at the $t-i$ quarter. Furthermore, we calculate market value of common equity as the product of quarter-end's close price and number of outstanding shares. The number of outstanding shares is adjusted for splits and reverse splits.

We construct COE, the cost of equity, assuming that CAPM holds, as the sum of the riskfree rate and beta times equity risk premium (ERP): 


$$
r_{i}=r_{f}+b_{i}\left[E\left(R_{M}\right)-r_{f}\right]=r_{f}+b_{i} \cdot E R P
$$

where, $r_{i}$ is the $\mathrm{BHC}$-specific $\mathrm{COE}, r_{f}$ is the risk free rate, $b_{i}$ is the $\mathrm{BHC}$-specific beta coefficient and $E\left(R_{M}\right)$ is the expected market return. We use ten-year Treasury bond yields as the risk-free rate. These values, taken from the U.S. Treasury website, are month-end values. Betas are calculated based on S\&P500 total return index. ${ }^{6}$ We calculate each BHC's returns from the return index prices. ${ }^{7}$ The source is Datastream and we use month-end observations. Moreover, we use the last 60 monthly observations (each one at the end of the respective month). We find ERP at Damodaran's website (based on S\&P500 at the end of each year as well), and because it is for the last quarter of each year, we adjust it for the other quarters as follows. After adding the year-end's risk-free rate to the respective ERP, we get the expected market return for that year. Furthermore, we assume that the expected market return is the same for all quarters of the year. Finally, we subtract the corresponding end of quarter risk-free rate from the expected market return so as to get the desired ERP.

We prefer return on common equity (ROCE) to ROE for the calculation of expected growth, because valuation models refer to common shareholders. Following the same logic, we use NI available to common shareholders instead of "general" NI and ROCE is given by:

$$
R O C E_{t}=\frac{(N I \text { available to common })_{t}}{B V(C E)_{t-1}}
$$

Finally, we calculate DPR, the dividend payout ratio, as the ratio of dividends to the BVCE. However, for consistency in the model, we use dividends and NI to common shareholders, and BVCE. Further adjustment is made for the amounts spent for share

\footnotetext{
${ }^{6}$ We use the market-value weighted S\&P500 index.

7 See Datastream definitions for further details about return index prices.
} 
repurchases, for which we assume that they are equally distributed across the quarters of a year (as stated in SEC 10-K filings). Additionally, because it is the event of dividend declaration that affects the price of a common share rather than the event of dividend payment, we use dividends declared instead of dividends paid. We find declaration dates at the NASDAQ website and BHCs websites. Hence, we have:

$$
M o d_{-} D P R=\frac{\text { Dividends declared }+S R / 4}{B V(C E)}
$$

where, $\mathrm{Mod}_{-} D P R$ is the modified DPR and $S R$ is the annual amount spent for share repurchases. For 2014:Q1, the last quarter in our sample, the amount spent for stock buybacks is taken from SEC 10-Q filings and is not divided by four, because it is a quarterly value already.

Substituting equations (4) and (5) into:

$$
\text { Exp_Growth_NI }=\left(1-\text { Mod }_{-} \text {DPR }\right) \cdot R O C E
$$

we get the expected growth of NI or Exp_Growth.

Regarding the macro variables: We use an index that captures the market sentiment. This index is constructed by the Federal Reserve Bank of St. Louis and captures a broad range of components indicating financial stress. The St. Louis Financial Stress Index (STLFSI) includes seven interest rates, six yield spreads and five other indicators. Negative values signify below-average financial market stress and positive values above-average financial market stress.

\subsection{Estimation}

First, we estimate (1) in order to find the fundamental values of PB ratios. We follow Pesaran et al. (1999) to determine the appropriate lag-length specification for the PMG 
estimation of 3DM and arrive at the following estimated restricted error-correction model (ECM) of equation (1):

$$
\begin{aligned}
\Delta P B_{i t}= & \phi_{i}\left(\begin{array}{l}
P B_{i, t-1}-\alpha_{0 i}-\alpha_{1} C_{i t}-\alpha_{2} E_{i t}-\alpha_{3} M_{i t}-\alpha_{4} C^{2}-\alpha_{5} E^{2} \\
-\alpha_{6} M^{2}-\alpha_{7} C E-\alpha_{8} C M-\alpha_{9} E M-\alpha_{10} C E M
\end{array}\right) \\
& +\delta_{1 i} \Delta P B_{t-1}+\sum_{j=0}^{1} \delta_{2 j i} \Delta E_{t-j}+\sum_{j=0}^{1} \delta_{3 j i} \Delta M_{t-j}^{2}+\sum_{j=0}^{1} \delta_{4 j i} \Delta C E_{t-j}+\sum_{j=0}^{1} \delta_{5 j i} \Delta C E M_{t-j}+\varepsilon_{i t}
\end{aligned}
$$

where, $P B$ is the market $\mathrm{PB}$ ratio, $\phi_{i}$ is the speed of adjustment, $\alpha_{0 i}$ is the bank-specific intercept, the remaining $\alpha$ 's are the common long-run coefficients, $\delta$ 's are the bank-specific short-run coefficients and $\varepsilon_{i t}$ is the error term. Inside the parentheses is the term $\left(P B_{\mathrm{i}, \mathrm{t}-1}-\right.$ $F P B_{\mathrm{i}, \mathrm{t}}$, where $F P B$ is the fundamental $\mathrm{PB}$ ratio estimated as the second-order Taylor expansion of equation (1), $C$ is the cost of equity, $E$ is the expected growth of net income, $M$ is the modified dividend payout ratio, and the remaining variables are Taylor expansion terms that have been selected using the Schwarz (1978) Bayesian Information Criterion (SBIC). ${ }^{8}$

By manipulating equation (7) in the long run, we arrive at:

$$
0=\phi\left(P B_{i}-F P B_{i}\right) \Rightarrow P B_{i}=\gamma \cdot F P B_{i} \text { since } \phi<0, \text { where } \gamma \text { is equal to } 1
$$

So, our first task is to test the hypothesis $H_{0}: \gamma=1$ in the long run, while controlling for other bank characteristics and macroeconomic determinants.

In order to explore whether our estimates for the fundamental value of $\mathrm{PB}$, i.e. $F P B$, capture significant part of the variation of market PB ratios, we extend (8) to the following panel data model:

\footnotetext{
8 In calculating fundamental PB ratios, we kept only observations with positive values of predicted PB ratios. This is in line with the literature, which excludes negative-multiple firms from analysis, eg. Athanassakos
} (2013). 


$$
\begin{aligned}
& P B_{i t}=\gamma \cdot F P B_{i t}+\sum_{j=1}^{J} g_{j} \cdot X_{j i t}+\sum_{k=1}^{K} h_{k} \cdot W_{k t}+\varepsilon_{i t}, \\
& \text { for } i=1, \ldots, N \& t=1, \ldots, T
\end{aligned}
$$

where, $X_{j}$ are time-varying bank characteristics, $W_{k}$ are variables summarizing the financial market stress and $\varepsilon_{i t}$ is the idiosyncratic error term.

We first need to check the order of integration of the variables we are going to use, then test for evidence of co-integration and, finally, estimate equations (7) and (9).

\subsection{Estimating Fundamental Values}

After estimating equation (7), we find that the average speed of adjustment, $\varphi$, is $-28.8 \%$, greater than -2 , and statistically significant, which means that a stable long-run equilibrium relationship dictated by (1) exists. ${ }^{9}$ The speed of adjustment is not a pooled estimate but rather the average of the corresponding coefficients across cross sections. The magnitude of $\varphi$ implies that about $29 \%$ of any deviation from the long run value is eliminated in one quarter and that a year after a shock about $25.7 \%$ of any disequilibrium still remains. After 14 quarters, the PB ratio has closed $99.1 \%$ of the gap from long-run equilibrium valuation. This implies that PB values are away from steady-state equilibrium for extended periods of time.

Calculating the partial derivatives of the long-run relationship with respect to the cost of equity, expected growth of net income and modified dividend payout ratio, we find that the three aforementioned variables present the expected signs at the largest part of the distribution. Therefore, $3 \mathrm{DM}$ is a valid stock market valuation model in our sample. ${ }^{10}$

\footnotetext{
9 Results regarding the estimation of equation (7) are in the Online Appendix.

10 A Hausman (1978) test provides evidence that long-run slope homogeneity holds. So, all BHCs in the panel seem to have the same long-run steady-state relation as assumed in 3DM.
} 


\subsection{Explaining Temporary Divergences of Market from Fundamental PB Ratios}

We proceed to explaining divergences of market from fundamental PB ratios in terms of bank-specific variables, and an index capturing both financial and macroeconomic conditions. The bank-specific variables are the leverage ratio (total assets over book value of common equity), bank size (log of assets) and bank opacity (details about opacity are in the next paragraph). The aforementioned index is constructed by the Federal Reserve Bank of St. Louis and captures a broad range of components indicating financial stress. ${ }^{11}$

\section{Figure 1: STLFSI}

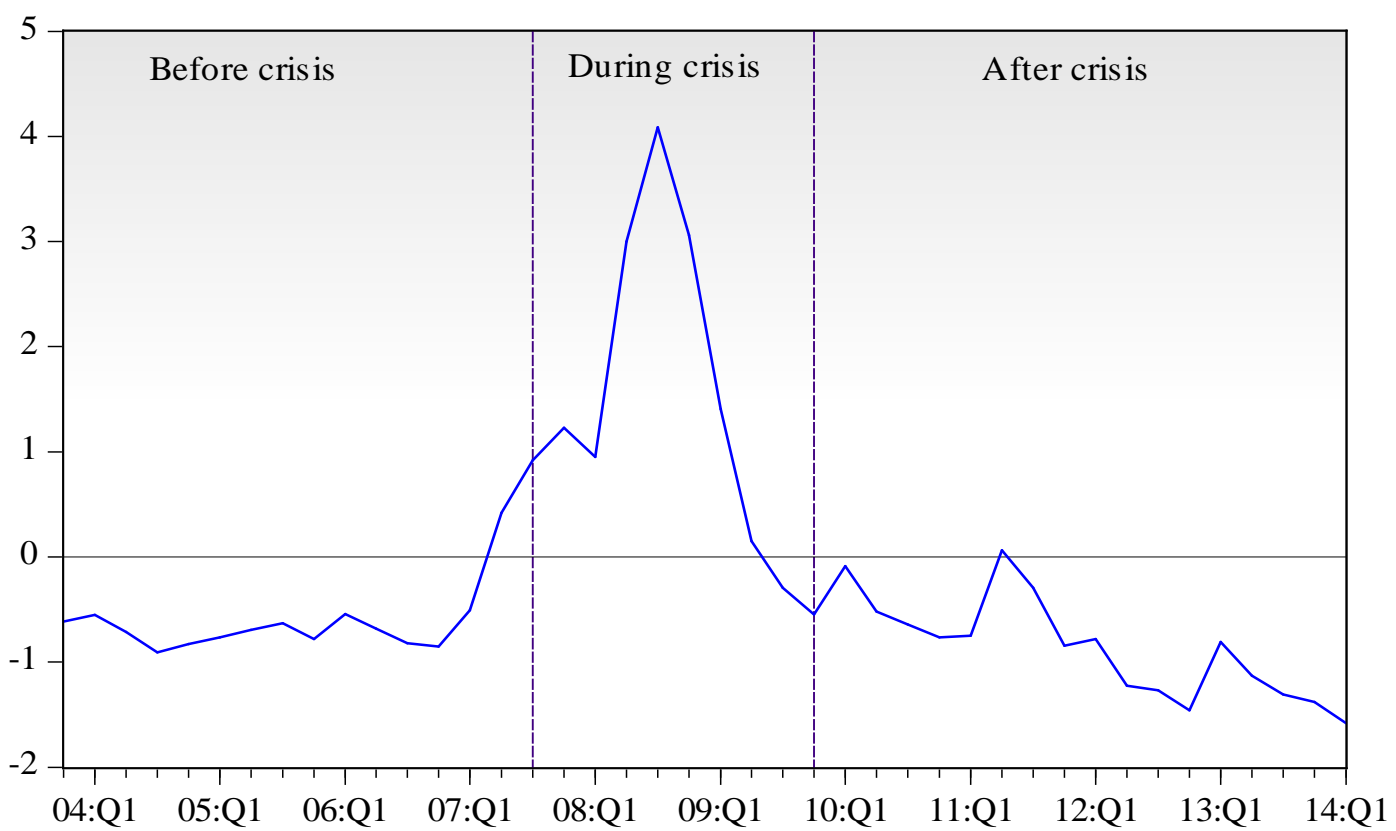

Notes: This is the St. Louis Financial Stress Index (STLFSI). Before-crisis period is from 2003:Q4 to 2007:Q2, during-crisis period from 2007:Q3 to 2009:Q4 and after-crisis period from to 2010:Q1 to 2014:Q1.

As we see in Figure 1, this index tracks down the crisis regimes very well. We believe that including the STLFSI variable in the right-hand side (RHS) of equation (9) controls quite well for aggregate financial market conditions.

11 Some other papers, which also use financial stress indices are that of Hippler and Hassan (2015), and Vasicek et al. (2017). 


\section{$\underline{\text { Opacity }}$}

The concept of opacity in the banking industry is that investors cannot observe the risks taken in the process of intermediation and, hence, they cannot distinguish adequately between healthy and risky banks. Opacity in the banking industry should be viewed as a hypothesis, rather than a fact. Morgan (2002), Hirtle (2006), Iannotta (2006), Bannier et al. (2010), and Haggard and Howe (2012) provide evidence that banks are more opaque than are non-banks. Flannery et al. (2013) show that banks are more opaque than non-banks during crisis periods only. This discussion points to the potential of exploring the role of opacity in valuation of the banks in our sample. Following Haggard and Howe (2012), we use as a measure of opacity the coefficient of determination, $\mathrm{R}^{2}$, of market-model excess-return regressions that use 52 weekly observations. In similar spirit, Jones et al. (2013) show that larger investments in opaque assets engender higher values for the logistic transform, which implies higher $\mathrm{R}^{2}$. Bai et al. (2017) employ the same logistic transformation to measure market synchronicity. Also, Hutton et al. (2009) show that increased values of their measure of earnings manipulation lead to lower idiosyncratic risk, which implies higher $\mathrm{R}^{2}$. We use the fourquarter moving average of $\mathrm{R}^{2}$ as our proxy of bank opacity, which we term OPACITY. ${ }^{12}$

How would a bank's opacity affect its market PB ratio diverging temporarily from its long-run fundamental value? Since investors are not able to measure accurately risks related to a bank that holds more opaque assets, this will negatively affect the demand of that stock. Alternatively, standard asset-pricing models predict that market participants unable to understand the nature of the assets in which they invest, would require a risk premium and hence, a discount on the asset price. Consequently, the market undervalues that bank and its $\mathrm{PB}$ ratio is lower. On the contrary, opaque assets may display overvaluation and thus, higher

\footnotetext{
${ }^{12}$ For robustness, we also use the $\mathrm{R}^{2}$ coefficient of the market-model regressions.
} 
values for the PB ratios. The inability of investors to assess the risks of that bank may positively affect the demand of that stock. Thus, high level of opacity of a bank may be rewarded from market participants. Therefore, demand increases and that bank stock is overvalued. Thus, the sign of opacity is empirically ambiguous. In this paper we explore whether opacity affects market value both in the long and in the short run.

\section{Size and Leverage}

Calomiris and Nissim (2014) contain an excellent discussion of the relationship between market valuation of banks and their size or leverage. The effect of size is expected to be positive for various reasons, a prominent one being implicit government subsidies. The effect of leverage on temporary divergences of market from fundamental PB ratios is ambiguous. On the one hand, lower leverage may be valued positively by the market as it provides a bank higher flexibility in operations and greater ability to grow by issuing debt without having to raise (relatively costly) external equity. On the other hand, higher leverage may be valued positively as an indication of efficient management that has maximized net benefits of leverage by exploiting profitable opportunities. Alternatively, leverage may be valued positively by the market due to implicit government subsidies.

\section{Empirical Results}

Using panel unit root tests for our variables, we find that the dependent variable is $I(1)$ and that in the RHS there is a mixture of $I(1)$ and $I(0)$ variables. Also, panel co-integration tests strongly reject the null hypothesis of no co-integration. ${ }^{13}$ Therefore, in order to estimate the long-run coefficients we use the panel co-integrating estimator of Phillips and Moon (1999), i.e. the panel Fully Modified OLS (pFMOLS) estimator with crisis-varying coefficients. Hence, we allow for different slopes of the RHS variables in equation (9) that depend on the

\footnotetext{
${ }^{13}$ Results of the panel unit root and co-integration tests are in the Online Appendix.
} 
regimes of the recent financial crisis, i.e. before-crisis (BC) period 2003:Q4-2007:Q2, duringcrisis (DC) period 2007:Q3-2009:Q4 and after-crisis (AC) period 2010:Q1-2014:Q1. ${ }^{14}$

$$
\begin{aligned}
P B_{i t} & =\gamma_{B C} \cdot F P B_{i t}+\gamma_{D C} \cdot F P B_{i t}+\gamma_{A C} \cdot F P B_{i t} \\
& +g_{1, B C} \cdot \text { OPACITY }+g_{1, D C} \cdot \text { OPACITY }+g_{1, A C} \cdot \text { OPACITY } \\
& +g_{2, B C} \cdot L E V E R A G E+g_{2, D C} \cdot L E V E R A G E+g_{2, A C} \cdot L E V E R A G E \\
& +h_{B C} \cdot S T L F S I+h_{D C} \cdot S T L F S I+h_{A C} \cdot S T L F S I+\varepsilon_{i t}, \\
\text { for } i & =1, \ldots, N \& t=1, \ldots, T
\end{aligned}
$$

where, $P B$ is the market $\mathrm{PB}$ ratio, $F P B$ the fundamental $\mathrm{PB}$ ratio as it estimated by $3 \mathrm{DM}$,

\begin{tabular}{|c|c|c|}
\hline Model specification & $I$ & II \\
\hline Co-integrating regressors & \multicolumn{2}{|c|}{ Coefficients (standard errors) } \\
\hline$F P B_{B C}$ & $1.095^{*}(0.096)$ & $1.025^{*}(0.087)$ \\
\hline$F P B_{D C}$ & $0.769^{*}(0.123)$ & $0.765^{*}(0.125)$ \\
\hline$F P B_{A C}$ & $0.744^{*}(0.085)$ & $0.739^{*}(0.083)$ \\
\hline $\mathrm{H}_{0}: \gamma_{B C}=1(p$-value in $\%)$ & 32.6 & 77.9 \\
\hline $\mathrm{H}_{0}: \gamma_{D C}=1(p$-value in $\%)$ & 6 & 6 \\
\hline $\mathrm{H}_{0}: \gamma_{A C}=1(p$-value in $\%)$ & 0.3 & 0.2 \\
\hline$O P A C I T Y_{B C}$ & $0.114(0.664)$ & $0.555(0.513)$ \\
\hline$O P A C I T Y_{D C}$ & $1.039(0.545)$ & $0.988^{* *}(0.449)$ \\
\hline$O P A C I T Y_{A C}$ & $-0.345(0.447)$ & $-0.287(0.389)$ \\
\hline$L E V E R A G E_{B C}$ & $-0.008(0.018)$ & $-0.019(0.016)$ \\
\hline
\end{tabular}
LEVERAGE is the leverage ratio, OPACITY is the variable measuring opacity and STLFSI is the market-stress index constructed by the Fed of St. Louis.

Table 1: Long-run results

Dependent variable: $P B$

14 For the market-stress index, STLFSI, we also allow for one slope since according to Figure 1, this index reproduces precisely the crisis regimes. As expected, results do not change. Moreover, we also do not include STLFSI in the RHS and results still exhibit robustness. All these results are in the Online Appendix. 


\begin{tabular}{|c|c|c|}
\hline$L E V E R A G E_{D C}$ & $-0.003(0.017)$ & $-0.006(0.017)$ \\
\hline$L E V E R A G E_{A C}$ & $0.02(0.017)$ & $0.017(0.017)$ \\
\hline$S T L F S I_{B C}$ & $-0.217(0.227)$ & $-0.381(0.209)$ \\
\hline$S T L F S I_{D C}$ & $-0.046(0.065)$ & $0.01(0.062)$ \\
\hline$S T L F S I_{A C}$ & $-0.216(0.151)$ & $-0.241(0.142)$ \\
\hline $\mathrm{R}^{2} / \operatorname{Adj} . \mathrm{R}^{2}$ (in \%) & 79.4 / 79.1 & $79.3 / 79$ \\
\hline Observations & 803 & 867 \\
\hline
\end{tabular}

Notes: We use the panel Fully Modified OLS (pFMOLS) estimator of Phillips and Moon (1999) with homogeneous variance-covariance matrix. We winsorize fundamental PB ratio, $F P B$, at $5^{\text {th }}$ and $95^{\text {th }}$ percentiles. The independent variable is the market $\mathrm{PB}$ ratio. The fundamental $\mathrm{PB}$ ratio, $F P B$, is the long-run value of $\mathrm{PB}$ ratio given by the long-run steady-state relation of equation (7). Model $I$ is the model, where the fourth order moving average of $\mathrm{R}^{2}$ coefficient is used for proxy of opacity. Model II is the model, where the $\mathrm{R}^{2}$ coefficient is used for proxy of opacity (or the first order moving average). We round to the third decimal. ${ }^{*}$ denotes $1 \%$ significance level and ${ }^{* *}$ denotes $5 \%$ significance level.

Table 1 shows that the gamma coefficients of the fundamental PB ratio, FPB, before and during the crisis are equal to 1 at the $10 \%$ and $5 \%$ significance level, respectively. Thus, controlling for leverage, opacity and market stress, we do not reject the hypothesis, $H_{0}: \gamma=1$, for these two aforementioned periods. Regarding the after-crisis period, the null hypothesis is not rejected for significance level close to $1 \%$. Also, leverage, opacity and STLFSI are statistically insignificant at least at the $1 \%$ significance level. So, the long-run values of fundamental PB ratio are properly calculated and 3DM seems to have priced risk, growth and cash flows effects, as they are proxied by cost of equity, expected growth of net income and modified dividend payout ratio, respectively, very well for all three regimes examined.

To test whether the financial crisis has altered investors' attitude towards bank valuation in the short run, or alternatively, to check whether there are temporary deviations of market PB ratio from its fundamental value while controlling for other bank characteristics, we employ a restricted error-correction model (R-ECM) under a crisis-varying co-integration 
framework. It is a first-differenced equation augmented by the first lag of the errorcorrection term (ECT) allowing for fixed time effects and bank-specific intercepts. ${ }^{15}$

$$
\begin{aligned}
\Delta P B_{i t} & =g_{1, B C} \cdot \Delta O P A C I T Y+g_{1, D C} \cdot \triangle O P A C I T Y+g_{1, A C} \cdot \Delta O P A C I T Y \\
& +g_{2, B C} \cdot \Delta L E V E R A G E+g_{2, D C} \cdot \Delta L E V E R A G E+g_{2, A C} \cdot \Delta L E V E R A G E \\
& +g_{3, B C} \cdot \Delta S I Z E+g_{3, D C} \cdot \Delta S I Z E+g_{3, A C} \cdot \Delta S I Z E \\
& +g_{4, B C} \cdot \Delta S T L F S I+g_{4, D C} \cdot \Delta S T L F S I+g_{4, A C} \cdot \Delta S T L F S I \\
& +\lambda_{B C} \cdot E C T_{i t-1}+\lambda_{D C} \cdot E C T_{i t-1}+\lambda_{A C} \cdot E C T_{i t-1}+\sum_{j=1}^{T} \alpha_{j} \cdot \tau_{j}+\sum_{k=1}^{N} \beta_{k} \cdot c_{k}+e_{i t}, \\
\text { for } i & =1, \ldots, N \& t=1, \ldots, T
\end{aligned}
$$

where, $P B$ is the market $\mathrm{PB}$ ratio, $L E V E R A G E$ is the leverage ratio, OPACITY is the opacity variable, SIZE is the $\log$ of assets, $\tau$ represents fixed time effects and $c_{k}$ individual BHC effects, and $e_{i t}$ is the idiosyncratic error term. ECT is the error-correction term constructed as the difference of $F P B$, i.e. the fundamental $\mathrm{PB}$ ratio as it estimated by $3 \mathrm{DM}$, from $P B$, i.e. the market $\mathrm{PB}$ ratio. Alternatively, it can be seen as the deviation of market $\mathrm{PB}$ ratios from the long-run equilibrium PB values. Therefore we have $E C T_{i t}=P B_{i t}-F P B_{i t}$. Moreover, we allow for different slopes for the crisis regimes. ${ }^{16}$

\section{Results for Different Categories of BHCs}

An interesting question is whether the GSIBs are systematically differently valued from the non-GSIBs in our sample, and second, whether market participants valued the BHCs that passed the stress test differently from the BHCs that failed these tests. Put differently: does controlling for the GSIBs and the stress tests, i.e. SCAP in 2009:Q2 and the CCARs in

\footnotetext{
15 We expect that the individual BHC effects are not jointly significant, because the $F P B$ from $3 \mathrm{DM}$ in $E C T$ includes the bank-specific intercepts. We do not drop them out from the equation, as we did in the pFMOLS estimator, because they may be statistically significant along with the fixed time effects.

${ }^{16}$ We did not include SIZE in the RHS for the long-run analysis since, at the steady state, there is no optimal size of a bank's assets.
} 
2012:Q1, 2013:Q1 and 2014:Q1, in equation (11) affect the results regarding the investors' attitude towards bank valuation in the short run?

Morgan et al. (2014) study the SCAP and find that it had a positive effect on stock prices. Similarly, Candelon and Sy (2015) show that early stress testing (SCAP) had a positive impact on stressed BHCs' returns, while the subsequent stress test (CCARs) effect decreased over time. Furthermore, Flannery et al. (2017) based on "beyond standard event study" results support evidence that stress testing disclosures provide information to investors and market participants. However, Neretina et al. (2014) find that the SCAP did not affect equity returns of the BHCs participating in this exercise, while the post-crisis stress tests seem to have barely affected equity returns. Their effects are small and statistically weak. In the same spirit, Glasserman and Tangirala (2016) suggest that the announcement of the stress test results did not inform the market.

The aforementioned papers rely on event-study techniques with daily data. ${ }^{17} \mathrm{We}$, on the other hand, have end-of-quarter data and we apply error-correction models augmented with impulse dummy variables for these events. Given the fact that our data are at a quarterly frequency, our results should not be compared to those attained from event-study methodologies that use daily returns to detect market movements. Instead, our results speak to the existence (or lack thereof) of lasting changes in market assessments in a period that includes the event in question: announcements of the stress tests. In addition, our focus is not on the actual market moves but rather in the degree of divergence of market PB ratios from their fundamental value. For example, if an event changes both fundamental and market PBs by the same amount, we will not see an effect of the stress-test dummy.

17 Glasserman and Tangirala (2016) also use regression models with projected losses for the BHCs that participated in the stress tests. 
We include fixed time effects as well as the dummies for 2009:Q2, 2012:Q1, 2013:Q1 and 2014:Q1, in our error-correction model of equation (11). This may provide evidence of market reaction to these exercises conducted by the Fed. Moreover, the dummy variables for SCAP and the successive CCAR exercises with the BHCs that failed these tests are intended to examine for evidence of market reaction captured in changes to the PB ratios.

Stress testing has become a systematic exercise conducted yearly by the Fed and it is well known that there could be limitations on the dividend policy of failed banks (see Panel B of Table 2). Neretina et al. (2014) suggest that banks participating in these exercises become better at passing them, and Glasserman and Tangirala (2016) show that there is a trend towards greater predictability of the stress tests outcomes. Also, Schuermann (2013) shows that BHCs are encouraged to mimic Fed's stress-testing exercises to pass them, and Goldstein and Sapra (2014) suggest that BHCs adjust their portfolios to pass the stress tests. ${ }^{18}$ Alternatively, these results suggest that investors can accurately forecast which banks will fail at the upcoming stress tests and thus, market participants may not be affected at all from the stress-testing public disclosures.

Table 2: Comparison of key variables between BHCs

\begin{tabular}{|c|c|c|c|c|}
\hline \multicolumn{5}{|l|}{ Panel A: non-GSIBs / GSIBs } \\
\hline \multicolumn{2}{|l|}{ Variables (median values) } & \multicolumn{2}{|c|}{ non-GSIBs / GSIBs } & \\
\hline Periods: & 2011:Q4-2014:Q1 & 2012:Q1 & 2013:Q1 & 2014:Q1 \\
\hline Market $P B$ ratio & $\mathbf{1 . 0 6 1 / 0 . 8 5 6}$ & 1.041/0.861 & 1.061/0.903 & $1.429 / 1.114$ \\
\hline Fundamental $P B$ ratio & $1.148 / \mathbf{1 . 3 2 1}$ & 1.169/1.399 & 1.098/1.222 & $1.1 / 1.099$ \\
\hline Mod_DPR & 1.104/1.043 & $\mathbf{0 . 9 8 3} / 0.858$ & 1.186/1.177 & $\mathbf{1 . 4 5 5} / 1.209$ \\
\hline Exp_Growth & $\mathbf{2 . 3 9 5 / 1 . 8 5 9}$ & 2.284/1.822 & 2.585/1.999 & 2.276/1.895 \\
\hline
\end{tabular}

18 On the other hand, Flannery et al. (2017) provide results, which show evidence that stress tests do not have impact on the formation of BHCs' assets. 


\begin{tabular}{l|c|ccc} 
COE & $9.439 / \mathbf{1 0 . 7 0 3}$ & $8.854 / \mathbf{9 . 5 1 4}$ & $9.465 / \mathbf{1 0 . 7 4 4}$ & $9.439 / \mathbf{1 1 . 6 2 1}$ \\
ROE & $\mathbf{2 . 4 6 8} / 1.873$ & $\mathbf{2 . 3 0 3} / 1.846$ & $\mathbf{2 . 5 8 8} / 2.001$ & $\mathbf{2 . 3 1 7} / 1.899$ \\
ROA & $\mathbf{0 . 2 4 9 / 0 . 1 7 4}$ & $\mathbf{0 . 2 3 4} / 0.209$ & $\mathbf{0 . 2 6} / 0.202$ & $\mathbf{0 . 2 5 8} / 0.178$ \\
LEVERAGE & $9.145 / \mathbf{1 0 . 2 6 4}$ & $9.203 / \mathbf{1 0 . 2 0 7}$ & $9.011 / \mathbf{1 0 . 2 8 1}$ & $8.98 / \mathbf{1 0 . 1 1}$ \\
OPACITY $(I)$ & $0.571 / 0.612$ & $0.629 / 0.673$ & $0.603 / 0.598$ & $0.409 / 0.556$ \\
OPACITY (II) & $0.545 / 0.602$ & $0.722 / 0.69$ & $0.507 / 0.523$ & $0.461 / 0.615$ \\
Valuation & $\mathbf{- 0 . 0 7 6 / - 0 . 3 5 2}$ & $\mathbf{- 0 . 1 1 / - 0 . 3 8 5}$ & $\mathbf{- 0 . 0 3 4} /-0.261$ & $\mathbf{0 . 3} / 0.014$ \\
\hline Pand B: pass /fail BHCs & & & &
\end{tabular}

Panel B: pass / fail BHCs

\begin{tabular}{|c|c|c|c|c|}
\hline \multirow{2}{*}{$\begin{array}{r}\text { Variables (median values) } \\
\text { Periods: }\end{array}$} & \multicolumn{4}{|c|}{ pass / fail BHCs } \\
\hline & 2009:Q2 & 2012:Q1 & 2013:Q1 & 2014:Q1 \\
\hline Market $P B$ ratio & 1.007/0.491 & $1.041 / 0.65$ & $0.979 / \mathbf{1 . 0 2 1}$ & $\mathbf{1 . 3 7 2} / 0.872$ \\
\hline Fundamental $P B$ ratio & $\mathbf{0 . 9 4 4 / 0 . 9 0 7}$ & 1.311/0.794 & 1.121/1.017 & $1.106 / 0.757$ \\
\hline Mod_DPR & $\mathbf{0 . 2 9 2 / 0 . 0 7 9}$ & $1.122 / 0.017$ & 1.181/1.016 & $\mathbf{1 . 4 7 7 / 0 . 1 6 4}$ \\
\hline Exp_Growth & $\mathbf{0 . 7 3 5} / 0.233$ & $2.284 / 1.236$ & $2.165 / 2.108$ & $2.279 / 1.644$ \\
\hline$C O E$ & $8.097 / 9.806$ & $8.999 / \mathbf{1 2 . 2 8 2}$ & $\mathbf{1 0 . 6 2 3 / 9 . 3 6 3}$ & $10.48 / \mathbf{1 2 . 4 2 8}$ \\
\hline$R O E$ & $\mathbf{0 . 7 3 7 / 0 . 2 3 4}$ & $\mathbf{2 . 3 0 3 / 1 . 2 3 8}$ & $2.206 / 2.125$ & 2.313/1.647 \\
\hline$R O A$ & $\mathbf{0 . 0 6 9} / 0.023$ & $\mathbf{0 . 2 2 9} / 0.139$ & $0.217 / 0.188$ & $\mathbf{0 . 2 3 8} / 0.17$ \\
\hline LEVERAGE & $12.257 / 11.473$ & $9.674 / \mathbf{1 0 . 7 1 3}$ & $9.81 / \mathbf{1 0 . 8 2 2}$ & $9.581 / 9.731$ \\
\hline OPACITY $(I)$ & $0.376 / 0.383$ & $0.629 / 0.673$ & $0.603 / 0.611$ & $0.485 / 0.475$ \\
\hline OPACITY (II) & $0.456 / 0.422$ & $0.711 / 0.731$ & $0.517 / 0.491$ & $0.491 / 0.494$ \\
\hline Valuation & $\mathbf{0 . 0 6 7 / - 0 . 4 5 8}$ & $-0.206 /-\mathbf{0 . 1 8 2}$ & $-0.127 / \mathbf{0 . 0 4}$ & $0.24 / \mathbf{0 . 1 5 3}$ \\
\hline
\end{tabular}

Notes: The Financial Stability Board (2011) published the list of the GSIBs for the first time in November 2011. Hence, we report statistics from 2011:Q4 in our sample. Fundamental PB ratio is the long-run value of PB ratio given by the long-run steady-state relation of equation (7). Mod_DPR is the modified dividend payout ratio of equation (5). Exp_Growth is the expected growth of net income given by equation (6). COE is the cost of equity given by equation (3). ROE is the return on common equity (ROCE) given by equation (4). ROA is the return on assets defined as the ratio of net income to common shareholders over total assets. LEVERAGE is the leverage ratio defined as the ratio of total assets over book value of common equity. OPACITY $(I)$ is the opacity variable measured as the fourth order moving average of $\mathrm{R}^{2}$ coefficient of market-model regressions. OPACITY (II) is the opacity variable measured as the $\mathrm{R}^{2}$ coefficient (or the first order moving average) of market-model 
regressions. Valuation is defined as the deviation of market PB ratio from its fundamental value over the longrun PB ratio. Mod_DPR,Exp_Growth, COE, ROE and ROA are in percentages.

In Table 2, we observe that GSIBs experienced lower market PB ratios, dividend payout ratios, expected growth of net income, return on equity, return on assets and valuation indexes than non-GSIBs in our sample. Also, they had greater leverage, cost of equity and fundamental PB values. ${ }^{19}$ Last but not least, regarding the long-run values of PB ratios, GSIBs had greater values than the non-GSIBs except for 2014:Q1, where they were equally valued with the non-GSIBs. Regarding the opacity variables there were periods, where GSIBs were more opaque than non-GSIBs and vice versa.

Table 2 also provides information about the BHCs that passed or failed the exercises conducted by the Fed. The BHCs, whose capital plans were not objected by the Fed, had greater fundamental PB values, dividend payout ratios, expected growth of net income, return on equity and return on assets than the BHCs that failed the corresponding stress tests. Regarding opacity, there is not a clear picture again. Furthermore, failed BHCs had greater values for leverage (for 2009:Q2 it holds with means, 12.596 vs 13.544) and lower values for market PB ratios (for 2013:Q1 it holds with means, 1.21 vs 1.021). Finally as we will show later, the BHCs that failed the stress-testing exercises, even though they had different bank characteristics, were not valued differently by the market.

Table 3 shows the results of estimating equation (11) augmented by a dummy variable for the GSIBs in our sample according to Financial Stability Board $(2013,2014)$, an interaction dummy taking the value of one for the quarter when the 2009 SCAP took place but only for the BHCs that failed the 2009 SCAP, and three interaction dummies taking the value of one

\footnotetext{
${ }^{19}$ For the long-run PB ratios at 2014:Q1, GSIBs had greater average values (1.726 vs 1.423) than non-GSIBs.
} 
for the quarter of the relevant stress test only for the BHCs, whose capital plans were objected at that particular test, i.e. the CCARs exercises of 2012, 2013 and $2014 .^{20}$

Table 3: Short-run effects (unrestricted slopes)

\begin{tabular}{|c|c|c|c|c|}
\hline \multicolumn{5}{|l|}{ Dependent variable: $\triangle P B$} \\
\hline \multirow{3}{*}{$\begin{array}{l}\text { Model Specification: } \\
\text { Co-integrating regressors }\end{array}$} & \multicolumn{2}{|c|}{$I$} & \multicolumn{2}{|c|}{$I I$} \\
\hline & \multicolumn{4}{|c|}{ Coefficients (robust standard errors) } \\
\hline & $C 1$ & $C 2$ & C3 & $C 4$ \\
\hline$\triangle O P A C I T Y_{B C}$ & $0.508(0.383)$ & $0.511(0.384)$ & $0.038(0.204)$ & $0.039(0.205)$ \\
\hline$\triangle O P A C I T Y_{D C}$ & $-0.537(0.719)$ & $-0.541(0.713)$ & $-0.225(0.246)$ & $-0.213(0.247)$ \\
\hline$\triangle O P A C I T Y_{A C}$ & $0.181(0.23)$ & $0.158(0.23)$ & $-0.041(0.133)$ & $-0.048(0.133)$ \\
\hline$\triangle L E V E R A G E_{B C}$ & $-0.07^{* *}(0.032)$ & $-0.07^{* *}(0.032)$ & $-0.13^{*}(0.028)$ & $-0.13^{*}(0.028)$ \\
\hline$\triangle L E V E R A G E_{D C}$ & $-0.056^{* *}(0.023)$ & $-0.059^{* *}(0.023)$ & $-0.057^{* *}(0.023)$ & $-0.06^{* *}(0.024)$ \\
\hline$\triangle L E V E R A G E_{A C}$ & $-0.08^{*}(0.02)$ & $-0.08^{*}(0.02)$ & $-0.078^{*}(0.02)$ & $-0.078^{*}(0.02)$ \\
\hline$\triangle S I Z E_{B C}$ & $0.916^{* *}(0.377)$ & $0.915^{* *}(0.377)$ & $1.346^{\prime}(0.423)$ & $1.344(0.424)$ \\
\hline$\triangle S I Z E_{D C}$ & $0.627(0.348)$ & $0.657(0.347)$ & $0.658(0.356)$ & $0.689(0.356)$ \\
\hline$\triangle S I Z E_{A C}$ & $0.739^{* *}(0.26)$ & $0.754^{*}(0262)$ & $0.729^{*}(0.259)$ & $0.747^{*}(0.261)$ \\
\hline$\triangle S T L F S I_{B C}$ & $-0.072(0.298)$ & $-0.062(0.298)$ & $-0.527(0.337)$ & $-0.506^{\prime \prime}(0.336)$ \\
\hline$\triangle S T L F S I_{D C}$ & $-0.034(0.025)$ & $-0.034(0.025)$ & $-0.051^{* *}(0.024)$ & $-0.051^{* *}(0.025)$ \\
\hline$\triangle S T L F S I_{A C}$ & $0.179^{* *}(0.057)$ & $0.18(0.058)$ & $0.177^{*}(0.059)$ & $0.178^{*}(0.06)$ \\
\hline$E C T_{t-1, B C}$ & $-0.12^{* * *}(0.057)$ & $-0.119^{* * *}(0.057)$ & $-0.123(0.051)$ & $-0.122^{*}(0.051)$ \\
\hline$E C T_{t-1, D C}$ & $-0.14^{*}(0.052)$ & $-0.142^{*}(0.052)$ & $-0.14^{*}(0.048)$ & $-0.142^{*}(0.048)$ \\
\hline$E C T_{t-1, A C}$ & $-0.093^{* *}(0.041)$ & $-0.092^{* *}(0.041)$ & $-0.092^{* *}(0.038)$ & $-0.09^{* *}(0.038)$ \\
\hline$\tau_{2009: \mathrm{Q} 2}$ & $0.316^{*}(0.082)$ & $0.389^{*}(0.085)$ & $0.3^{*}(0.083)$ & $0.371^{*}(0.086)$ \\
\hline$\tau_{2012: \mathrm{Q} 1}$ & $0.412^{*}(0.044)$ & $0.413^{*}(0.046)$ & $0.421^{*}(0.044)$ & $0.419^{*}(0.045)$ \\
\hline
\end{tabular}

20 The BHC, Ally, which did not pass the DFAST 2013 is not publicly traded and thus, is not included in our sample. The BHC, Zions, which did not pass the DFAST 2014 failed the CCAR 2014 and it is incorporated in the dummy variable for the CCAR 2014. So, we do not include dummy variables for the DFAST exercises. 


\begin{tabular}{|c|c|c|c|c|}
\hline$\tau_{2013: \mathrm{Q} 1}$ & $0.255^{*}(0.043)$ & $0.259^{*}(0.046)$ & $0.249^{*}(0.041)$ & $0.252^{*}(0.044)$ \\
\hline$\tau_{2014: Q 1}$ & $0.342^{*}(0.057)$ & $0.348^{*}(0.059)$ & $0.344^{*}(0.058)$ & $0.346^{*}(0.059)$ \\
\hline $\mathrm{D}_{\mathrm{SCAP}-\mathrm{F}}$ & - & $-0.198^{* *}(0.099)$ & - & $-0.192(0.1)$ \\
\hline $\mathrm{D}_{\mathrm{CCAR} 12-\mathrm{F}}$ & - & $-0.002(0.035)$ & - & $-0.013(0.039)$ \\
\hline $\mathrm{D}_{\mathrm{CCAR} 13-\mathrm{F}}$ & - & $-0.064(0.047)$ & - & $-0.076(0.048)$ \\
\hline $\mathrm{D}_{\mathrm{CCAR} 14-\mathrm{F}}$ & - & $-0.066(0.049)$ & - & $-0.073(0.055)$ \\
\hline $\mathrm{D}_{\mathrm{GSIB}}$ & - & $0.004(0.027)$ & - & $0.016(0.029)$ \\
\hline $\mathrm{R}^{2}($ in $\%)$ & 38 & 38.3 & 38.5 & 38.7 \\
\hline $\mathrm{H}_{0}: \underline{\alpha^{\prime} s}(p$-value in $\%)$ & 0 & 0 & 0 & 0 \\
\hline $\mathrm{H}_{0}: \underline{\beta \prime} s(p$-value in $\%)$ & 62.5 & 69.3 & 24.2 & 30.8 \\
\hline $\mathrm{H}_{0}: \underline{\alpha \prime s} \& \beta^{\prime} s(p$-value in $\%)$ & 0 & 0 & 0 & 0 \\
\hline $\mathrm{H}_{0}:$ gstress $(p$-value in $\%)$ & - & 15 & - & 12 \\
\hline \multirow[t]{2}{*}{$\mathrm{H}_{0}: \underline{\text { mktinfo }}(p$-values in $\%)$} & 0 & 0.1 & 0 & 0 \\
\hline & 0 & 0 & 0 & 0 \\
\hline Observations & 866 & 866 & 936 & 936 \\
\hline
\end{tabular}

Notes: We winsorize fundamental $\mathrm{PB}$ ratio, $F P B$, at $5^{\text {th }}$ and $95^{\text {th }}$ percentiles. The independent variable is the first difference of market PB ratio. Model $I$ is the model, where the fourth order moving average of $\mathrm{R}^{2}$ coefficient is used for proxy of opacity. Model II is the model, where the $\mathrm{R}^{2}$ coefficient is used for proxy of opacity (or the first order moving average). $\mathrm{D}_{\mathrm{SCAP}-\mathrm{F}}, \mathrm{D}_{\mathrm{CCAR} 12-\mathrm{F}}, \mathrm{D}_{\mathrm{CCAR} 13-\mathrm{F}}$, and $\mathrm{D}_{\mathrm{CCAR} 14-\mathrm{F}}$ are interaction dummies taking the value of one for the quarter of the relevant stress test only for the BHCs that failed that particular stress test. The null hypothesis of $\underline{\alpha \text { 's }}$ is the joint non-significance of the fixed time effects. The null hypothesis of $\underline{\beta}$ 's is the joint non-significance of the individual BHC effects. The null hypothesis of $\underline{\alpha} s \& \beta$ 's is the joint non-significance of the fixed time effects and the individual intercepts. The null hypothesis of gstress checks whether the dummy variable for the GSIB status, and the dummy variables of the BHCs that failed the SCAP and the CCAR exercises are jointly non-significant. The null hypothesis of $\underline{m k t i n f o}$ checks the equality of the average value, G1, of the time dummies corresponding to SCAP and CCAR 2012, 2013 and 2014, and the average value, G2, of the rest time dummies against the alternative hypothesis that G1 is greater than G2. The first row of $\underline{m k \text { tinfo }}$ test contains the $p$-values of the $t$-tests incorporating the covariance effect, while the second row contains the $p$-values of the $t$-tests assuming a zero-covariance effect. Both $t$-tests for $\underline{\text { mktinfo }}$ assume unequal variances and follow a student's- $t$ distribution with degrees of freedom given by the Welch- 
Satterthwaite equation. We round to the third decimal. * denotes $1 \%$ significance level and ${ }^{* *}$ denotes $5 \%$ significance level.

In Table 3, we can see that leverage has a negative effect on investors' beliefs regarding the $\mathrm{PB}$ ratio. Higher leverage is associated with lower market $\mathrm{PB}$ ratios relative to fundamental values. Regarding size, large banks enjoy higher market PB ratios relative to fundamentals. Our results indicate that the market valued size positively before and after the crisis, and that this relationship disappeared temporarily during the crisis. Our results are consistent with temporarily diminished expectations by investors that these large and systemic BHCs would benefit from government bailouts. The regulatory actions to address the "Too Big to Fail" problems to financial stability seem not to have had a lasting effect. Moreover, we find that opacity does not affect market participants' valuation at all throughout the period covered by our sample for the large and systemic U.S. BHCs.

The average speed of adjustment is around $11.8 \%$ in each of the four specifications (see columns $\mathrm{C} 1$ to $\mathrm{C} 4$ of Table 3 ), which means that a year (or 4 quarters) after a shock occurs, about $60.5 \%$ of any disequilibrium remains. Time effects are jointly significant and, as anticipated, the individual BHC effects are jointly zero. However, time effects and bankspecific intercepts are highly significant when we test them jointly.

Testing whether the average effect of the four quarters corresponding to stress tests public disclosures is greater than the average effect of the other quarters, we find strong evidence in favor of the information value of the stress tests (see $\underline{\text { mktinfo }}$ tests in Tables 3 and 4). ${ }^{21}$ Hence, similarly to Morgan et al. (2014), Candelon and Sy (2015), and Flannery et al. (2017), we find that the stress tests conducted by the Fed provided information to market participants.

\footnotetext{
21 The mktinfo test tests whether the average value, G1, of the time dummies corresponding to the 2009 SCAP, and 2012, 2013 and 2014 CCARs exercises, is equal to the average value, G2, of the other time dummies. The alternative hypothesis is that G1 is greater than $\mathrm{G} 2$.
} 
In quarters that contained released results on these stress tests market participants revalued the BHCs participating in these exercises relative to fundamentals. Also, our results are not in the same spirit as those of Neretina et al. (2014), who show within an event-study framework that post-crisis stress-testing had little impact on equity returns, or those of Glasserman and Tangirala (2016), who show that stress-testing public disclosures have become arguably less informative over time. Of course, as we pointed out earlier, the time horizon of potential impact in our study is different since we have quarterly observations.

We move on to the question whether the market displayed any incremental, contemporaneous reaction for the BHCs that failed the stress tests. We find that the market did not adjust differentially the valuation of BHCs, whose capital plans were objected by the Fed in the CCAR 2012, 2013 and 2014 exercises. However, we find weak evidence in favor of incremental market adjustment in PB ratios of BHCs that failed the 2009 SCAP. Moreover, the null hypothesis of the joint non-significance of the dummy variable for the GSIB status, and the dummy variables of the BHCs that failed the SCAP and the CCAR exercises, is not rejected at any convenient significance level. In other words, we did not detect divergences of market from fundamental valuation that was particular to the PB ratios of the GISBs or of the BHCs that failed the stress tests.

To check robustness, we impose a common slope across all three time periods delineated by the crisis for all explanatory variables. The results do not change. Table 4 presents the results with the restricted slopes.

Table 4: Short-run effects (restricted slopes)

\begin{tabular}{l|c}
\hline Dependent variable: $\triangle P B$ & $I$ \\
\hline Model Specification: & Coefficients (robust standard errors) \\
\hline Co-integrating regressors & \\
\hline
\end{tabular}




\begin{tabular}{|c|c|c|c|c|}
\hline & $C 1$ & $C 2$ & $C 3$ & $C 4$ \\
\hline$\triangle O P A C I T Y$ & $0.134(0.254)$ & $0.129(0.254)$ & $-0.078(0.112)$ & $-0.077(0.112)$ \\
\hline$\triangle L E V E R A G E$ & $-0.063(0.016)$ & $-0.064^{\prime}(0.017)$ & $-0.08 *(0.017)$ & $-0.082 *(0.017)$ \\
\hline$\triangle S I Z E$ & $0.734^{*}(0.222)$ & $0.746^{*}(0.222)$ & $1.005^{*}(0.257)$ & $1.016(0.257)$ \\
\hline$\triangle S T L F S I$ & $-0.047^{*}(0.023)$ & $-0.047^{*}(0.023)$ & $-0.05^{\prime}(0.025)$ & $-0.05^{* * 1}(0.025)$ \\
\hline$E C T_{t-1}$ & $-0.117^{* *}(0.046)$ & $-0.118^{* *}(0.047)$ & $-0.12^{*}(0.043)$ & $-0.12(0.043)$ \\
\hline$\tau_{2009: \mathrm{Q} 2}$ & $0.305^{*}(0.082)$ & $0.376^{*}(0.087)$ & $0.277^{*}(0.088)$ & $0.357^{*}(0.093)$ \\
\hline$\tau_{2012: \mathrm{Q} 1}$ & $0.406^{*}(0.048)$ & $0.413^{*}(0.049)$ & $0.408^{*}(0.049)$ & $0.409^{\prime}(0.051)$ \\
\hline$\tau_{2013: \mathrm{Q} 1}$ & $0.384^{*}(0.055)$ & $0.395^{*}(0.059)$ & $0.382^{*}(0.055)$ & $0.388^{\prime}(0.059)$ \\
\hline$\tau_{2014: \mathrm{Q} 1}$ & $0.285^{*}(0.05)$ & $0.297^{*}(0.051)$ & $0.287^{*}(0.053)$ & $0.293^{*}(0.055)$ \\
\hline $\mathrm{D}_{\mathrm{SCAP}-\mathrm{F}}$ & - & $-0.188^{* *}(0.095)$ & - & $-0.211^{*}(0.095)$ \\
\hline $\mathrm{D}_{\mathrm{CCAR} 12-\mathrm{F}}$ & - & $-0.006(0.031)$ & - & $-0.003(0.036)$ \\
\hline $\mathrm{D}_{\mathrm{CCAR} 13-\mathrm{F}}$ & - & $-0.059(0.049)$ & - & $-0.07(0.05)$ \\
\hline $\mathrm{D}_{\text {CCAR 14-F }}$ & - & $-0.058(0.046)$ & - & $-0.064(0.049)$ \\
\hline $\mathrm{D}_{\mathrm{GSIB}}$ & - & $-0.02(0.028)$ & - & $-0.002(0.029)$ \\
\hline $\mathrm{R}^{2}$ (in \%) & 37.2 & 37.4 & 37 & 37.3 \\
\hline $\mathrm{H}_{0}: \underline{\alpha \prime s}(p$-value in $\%)$ & 0 & 0 & 0 & 0 \\
\hline $\mathrm{H}_{0}: \underline{\beta} s(p$-value in $\%)$ & 74.2 & 79.1 & 30.4 & 38.5 \\
\hline $\mathrm{H}_{0}: \underline{\alpha{ }^{\prime} s \& \beta^{\prime} s}(p$-value in $\%)$ & 0 & 0 & 0 & 0 \\
\hline $\mathrm{H}_{0}:$ gstress $(p$-value in $\%)$ & - & 17.5 & - & 9.6 \\
\hline \multirow[t]{2}{*}{$\mathrm{H}_{0}: \underline{\text { mktinfo }}$ ( $p$-values in $\left.\%\right)$} & 0 & 0 & 0.3 & 0 \\
\hline & 0 & 0 & 0 & 0 \\
\hline Observations & 866 & 866 & 936 & 936 \\
\hline
\end{tabular}

Notes: We winsorize fundamental $\mathrm{PB}$ ratio, $F P B$, at $5^{\text {th }}$ and $95^{\text {th }}$ percentiles. The independent variable is the first difference of market PB ratio. Model $I$ is the model, where the fourth order moving average of $\mathrm{R}^{2}$ coefficient is used for proxy of opacity. Model II is the model, where the $\mathrm{R}^{2}$ coefficient is used for proxy of opacity (or the first order moving average). $\mathrm{D}_{\mathrm{SCAP}-\mathrm{F}}, \mathrm{D}_{\mathrm{CCAR} 12-\mathrm{F}}, \mathrm{D}_{\mathrm{CCAR} 13-\mathrm{F}}$, and $\mathrm{D}_{\mathrm{CCAR} 14-\mathrm{F}}$ are interaction dummies taking the value of one for the quarter of the relevant stress test only for the BHCs that failed that particular stress test. The null hypothesis of $\underline{\alpha \text { 's }}$ is the joint significance of the fixed time effects. The null hypothesis of 
$\underline{\beta}$ 's is the joint non-significance of the individual BHC effects. The null hypothesis of $\underline{\alpha \text { 's \& } \beta \text { 's }}$ is the joint nonsignificance of the fixed time effects and the individual intercepts. The null hypothesis of gstress checks whether the dummy variable for the GSIB status, and the dummy variables of the BHCs that failed the SCAP and the CCAR exercises are jointly non-significant. The null hypothesis of $\underline{\text { mktinfo }}$ checks the equality of the average value, G1, of the time dummies corresponding to SCAP and CCAR 2012, 2013 and 2014, and the average value, G2, of the rest time dummies against the alternative hypothesis that G1 is greater than G2. The first row of $\underline{m k \text { tinfo }}$ test contains the $p$-values of the $t$-tests incorporating the covariance effect, while the second row contains the $p$-values of the $t$-tests assuming a zero-covariance effect. Both $t$-tests for $\underline{m k t i n f o}$ assume unequal variances and follow a student's- $t$ distribution with degrees of freedom given by the WelchSatterthwaite equation. We round to the third decimal. " denotes $1 \%$ significance level and ${ }^{* *}$ denotes $5 \%$ significance level.

To sum up, a positive (negative) shock to fundamental valuation for these large and systemic BHCs leads to market under-valuation (over-valuation) as the market is slow to react to it. Furthermore, market valuation relative to fundamental valuation is higher for larger BHCs, whereas the opposite holds for BHCs with higher leverage. On the other hand, bank opacity does not seem to affect market participants' valuations of PB ratios relative to their fundamentals. Moreover, our results for the earlier (SCAP) and post-crisis stress-testing processes indicate that the market received valuable information that led to higher PB valuations. On the other hand, we find strong evidence that the BHCs that failed in the CCARs were not valued differently by the market. Regarding the 2009 SCAP, three out of four model specifications (see column C2 of Table 3, and columns C2 and C4 of Table 4) support that the BHCs that were in need to raise their capital were hit by market participants.

\section{Conclusions}

The stock market valuation of large and systemic U.S. BHCs has a stable long-run relationship to three fundamental variables: the cost of equity, the expected growth of net income and the modified dividend payout ratio. At any given point in time, however, there is 
a large heterogeneity in the degree to which current price-to-book ratios of equity are temporarily above or below their long-run equilibrium valuation. These divergences are created as market participants under-react to shocks in fundamentals. Furthermore, they are rather persistent over time with a fraction of $12 \%$ to $30 \%$ of the gap closing each quarter. The degree of market under-reaction to shocks, and thus, of over- or under-valuation, is related to bank characteristics such as leverage and size but not to their opacity. We provide evidence that the financial crisis has not altered investors' attitudes towards bank characteristics. In particular, before, during, and after the crisis, investors in large and systemic U.S. BHCs seemed to penalize leverage, albeit temporarily. Before and after the crisis, they reward size in the short run but during the crisis this pattern disappeared. We also show that opacity has no effect at all in our sample either in the short run or in the long run. Finally, we find that the whole stress-testing procedure has positively affected market PB ratios, while only the public disclosures of SCAP in 2009 seem to have negatively influenced market participants' valuation of those BHCs that failed the test.

\section{Acknowledgements}

We would like to thank Spyros Skouras, Mathias Hoffman, Edwin Neave, George Dikos, Manthos Delis, several anonymous referees and seminar participants at the 2015 World Finance Conference, University of Zurich, ETH-Zurich, ALBA Graduate Business School at the American College of Greece, Luxembourg School of Finance, 2015 CRETE conference, 2015 Paris Financial Management Conference, 2016 meetings of the Multinational Finance Association and University of Glasgow for useful comments, and Conrad Landis for his assistance with the Datastream database. This work was supported by a research grant from Athens University of Economics and Business, and a doctoral research scholarship from the General Secretariat for Research and Technology (GSRT) and the Hellenic Foundation for Research and Innovation (HFRI). 


\section{References}

Athanassakos, G., 2013. Are Negative P/E and P/B ratios Firms Different? Business \& Financial Affairs 2:109, June. doi:10.4172/2167-0234.1000109.

Bai, X., Hu, N., Liu, L., Zhu, L., 2017. Credit Derivatives and Stock Return Synchronicity. Journal of Financial Stability 28, February, 79-90.

Bannier, C. E., Behr, P., Guttler, A., 2010. Rating Opaque Borrowers: Why Are Unsolicited Ratings Lower. Review of Finance 14 (2), April, 263-294.

Bertsatos, G., Sakellaris, P., 2016. A Dynamic Model of Bank Valuation. Economics Letters 145, August, 15-18.

Calomiris, C. W., Nissim, D., 2014. Crisis-Related Shifts in the Market Valuation of Banking Activities. Journal of Financial Intermediation 23 (3), July, 400-435.

Candelon, B., Sy, A. N. R., 2015. How Do Markets React to Stress Tests? IMF Working Paper 15/75, April.

Financial Stability Board, 2011. Policy Measures to Address Systemically Important Financial Institutions, November.

Financial Stability Board, 2013. 2013 Update of Group of Global Systemically Important Banks (G-SIBs), November.

Financial Stability Board, 2014. 2014 Update of List of Global Systemically Important Banks (G-SIBs), November.

Flannery, M. J., Kwan, S. H., Nimalendran, M., 2013. The 2007-09 Financial Crisis and Bank Opaqueness. Journal of Financial Intermediation 22 (1), January, 55-84. 
Flannery, M. J., Hirtle, B., Kovner, A., 2017. Evaluating the Information in the Federal Reserve Stress Tests. Journal of Financial Intermediation 29 (1), January, 1-18.

Glasserman, P., Tangirala, G., 2016. Are the Federal Reserve's Stress Test Results Predictable? Journal of Alternative Investments 18 (4), Spring, 82-97.

Goldstein, I., Sapra, H., 2014. Should Banks' Stress Test Results be Disclosed? An analysis

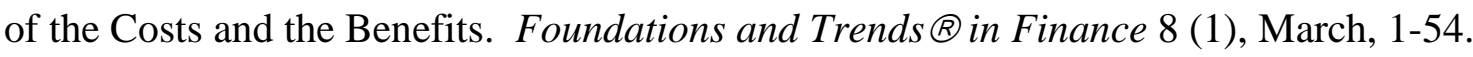

Haggard, K. S., Howe, J. S., 2012. Are Banks Opaque? International Review of Accounting, Banking and Finance 4 (1), Spring, 51-72.

Hausman, J. A., 1978. Specification Tests in Econometrics. Econometrica 46 (6), 12511271.

Hippler, W. J., Hassan, M. K., 2015. The Impact of Macroeconomic and Financial Stress on the U.S. Financial Sector. Journal of Financial Stability 21, December, 61-80.

Hirtle, B., 2006. Stock Market Reaction to Financial Statement Certification by Bank Holding Company CEOs. Journal of Money, Credit and Banking 38 (5), August, 1263-1292.

Hutton, A. P., Marcus, A. J., Tehranian, H., 2009. Opaque Financial Reports, R $^{2}$, and Crash Risk. Journal of Financial Economics 94 (1), October, 67-86.

Iannotta, G., 2006. Testing for Opaqueness in the European Banking Industry: Evidence from Bond Credit Ratings. Journal of Financial Services Research 30 (3), December, 287309.

Jones, J., Lee, W., Yeager, T., 2013. Valuation and Systemic Risk Consequences of Bank Opacity. Journal of Banking and Finance 37 (3), 693-706. 
Morgan, D. P., 2002. Rating banks: Risk and Uncertainty in an Opaque Industry. The American Economic Review 92 (4), September, 874-888.

Morgan, D. P., Peristiani, S., Savino, V., 2014. The Information Value of the Stress Test. Journal of Money, Credit and Banking 46 (7), October, 1479-1500.

Neretina, E., Sahin, C., Haan, J., 2014. Banking Stress Test Effects on Returns and Risks. Netherlands Central Bank - Research Department. DNB Working Paper 419, April.

Pesaran, M. H., Shin, Y., Smith, R. P., 1999. Pooled Mean Group Estimation of Dynamic Heterogeneous Panels. Journal of the American Statistical Association 94 (446), June, 621634.

Phillips, P. C. B., Moon, H. R., 1999. Linear Regression Limit Theory for Nonstationary Panel Data. Econometrica 67 (5), September, 1057-1111.

Schuermann, T., 2013. The Fed's Stress Tests Add Risk to the Financial System. Wall Street Journal, March 19, 2013. The web link is:

https://www.wsj.com/articles/SB10001424127887324532004578362543899602754

Schwarz, G., 1978. Estimating the Dimension of a Model. Annals of Statistics 6 (2), March, 461-464.

Vasicek, B., Zigraiova, D., Hoerberichts, M., Vermeulen, R., Smidkova, K., Haan, J., 2017. Leading Indicators of Financial Stress: New Evidence. Journal of Financial Stability 28, 240-257. 